\title{
AN EXPLORATION OF ESSENTIAL FACTORS THAT INFLUENCE MUSIC STREAMING ADOPTION AND THE INTENTION TO ENGAGE IN DIGITAL PIRACY
}

\author{
William Hampton-Sosa, Ph.D. \\ Brooklyn College, City University of New York \\ 2900 Bedford Avenue \\ Brooklyn, NY 11210 \\ whamptonsosa@brooklyn.cuny.edu
}

\begin{abstract}
Preventing unauthorized downloading and other forms of digital piracy has been a persistent challenge for many who own the rights to digital content. Attempts to counter digital piracy with strategies based on deterrence, ethical arguments, psychosocial considerations, or technical measures have been effective, but only to a limited extent. The increasing popularity of music streaming systems, however, offers additional opportunities to experiment with novel business models and value propositions that may discourage digital piracy. The results of this quasi experiment involving 139 subjects indicated that for music streaming systems, perceived system and information quality, perceived usefulness, perceived ease of use, and perceived enjoyment contributed to purchasing intention. These factors also influenced unauthorized downloading intention; however, an expected negative relationship between perceived enjoyment of the music streaming system and unauthorized downloading intention, a form of digital piracy, was not supported.
\end{abstract}

Keywords: Music Streaming, Digital Piracy, System Quality, Information Quality, Usability, Enjoyment, Quantitative

\section{INTRODUCTION}

The widespread availability of inexpensive and easy to use broadband computing technology, the emergence of numerous peer-to-peer file-sharing services, the increasing adoption of cloud computing storage, and the 
proliferation of private networks have made it possible to share massive amounts of digital information with large numbers of individuals. Efforts to shut down online directory services, such as the Pirate Bay, which facilitates the search for unauthorized content, have been repeatedly defeated. As recently as October 2016, notwithstanding sporadic disruptions in service, the Pirate Bay site managers have continued to find ways of keeping the site in operation ${ }^{1}$.

Challenges posed by large-scale digital piracy have affected the markets for all types of products, including music, movies, games, software, and books. This has upended the long established business models for product rights owners (PROs). Quantifying the magnitude of digital piracy and its effects has always been difficult, and figures tend to vary widely, depending on the region and on the method of assessment. Nevertheless, we do have some estimates. Bender and Wang found that a one percent increase in the music piracy rate results in a 0.6 percent decrease in music sales ${ }^{2}$. They also found that a one percent increase in the Internet penetration rate results in a greater than one percent decrease in music sales ${ }^{2}$.

In one of the more recent detailed studies, the NetNames Piracy Analysis Group found that while declines in digital piracy have been noted in some countries, copyright infringement remains flat or continues to grow in many parts of the world in terms of the number of users involved, the amount of infringing content available online, and the amount of Internet bandwidth devoted to unauthorized content ${ }^{3}$. In the three regions that make up the vast majority of Internet users and bandwidth consumed - North America, Europe, and the Asia-Pacific region - infringing bandwidth use between 2010 and 2012 increased by $159.3 \%$ and represented $23.8 \%$ of total bandwidth consumption ${ }^{3}$. The NetNames Piracy Analysis Group also found that the number of Internet users explicitly seeking infringing content during 2013 in those three regions rose by $9.9 \%$ and represented a quarter of the total Internet population ${ }^{3}$. Figures 1 and 2 illustrate the amount of file sharing in petabytes in the U.S. and around the globe. The rate of increase appears to be moderating, but the amount of content being shared remains quite large. 


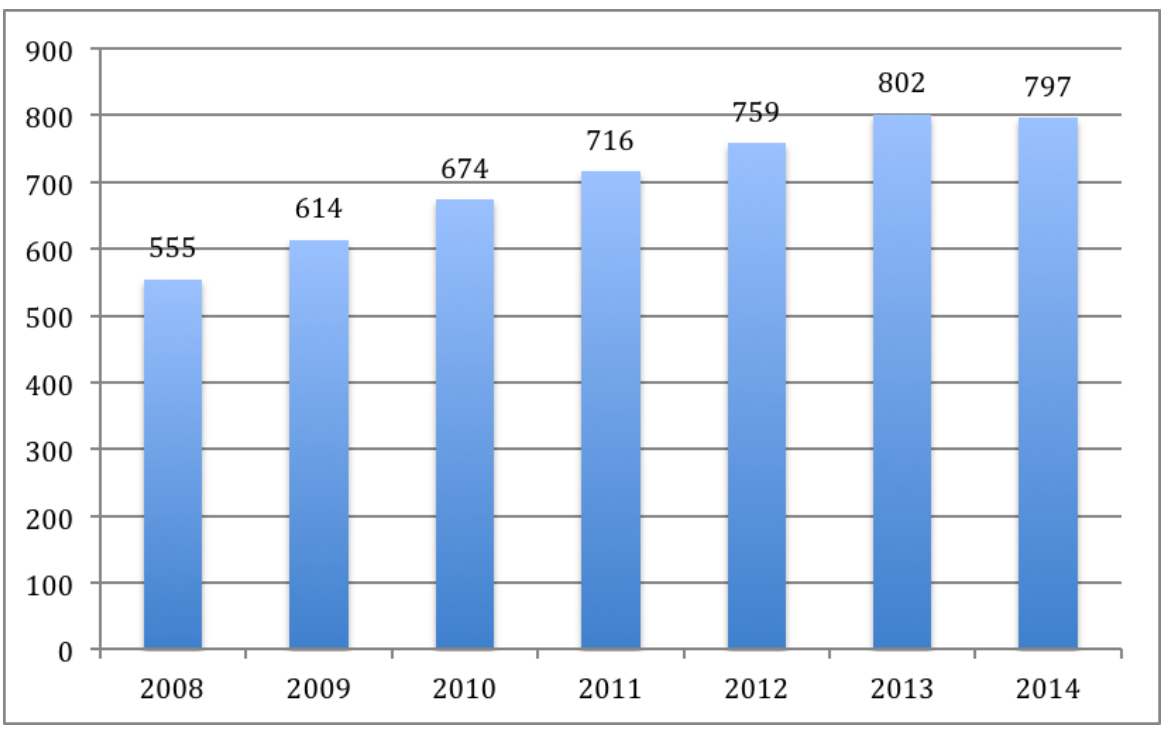

Sources: Cisco Visual Networking Index: Forecast and Methodology 2008-2013, 2013-2018, 2014-2019 ${ }^{4}$

Figure 1. File sharing in Petabytes per month in North America

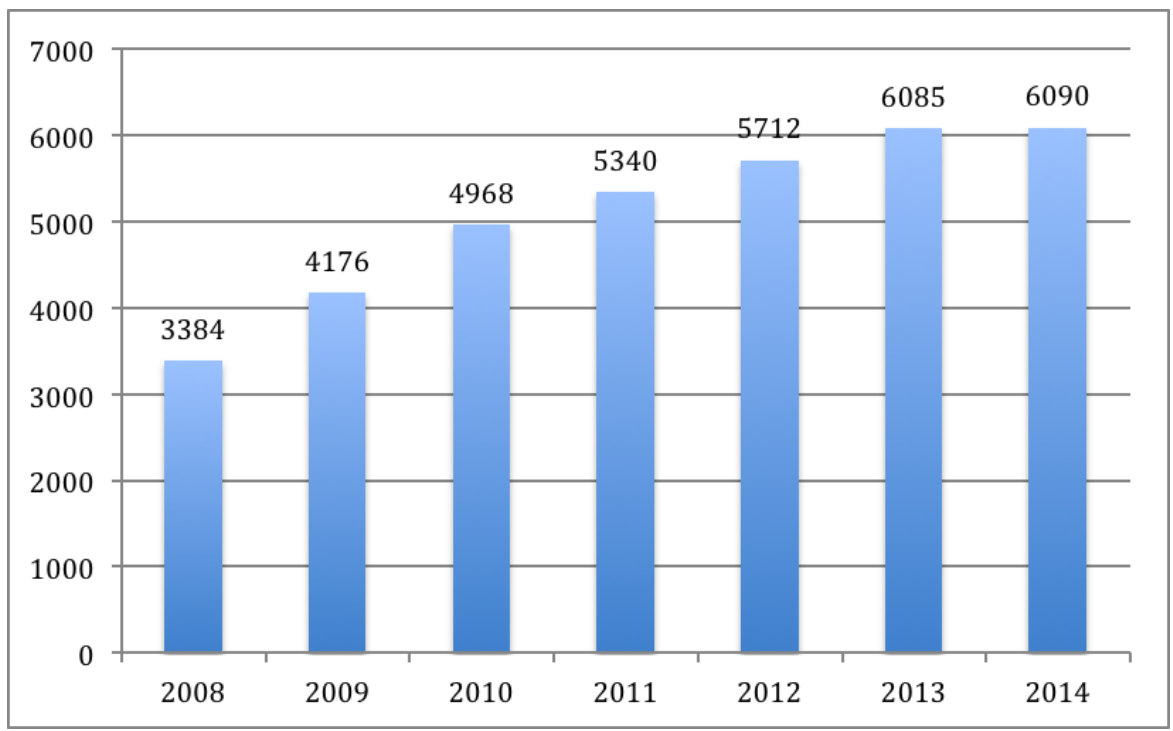

Sources: Cisco Visual Networking

Index:Forecast and Methodology 2008-2013, 2013-2018, 2014-2019 ${ }^{4}$

Figure 2. File sharing in Petabytes per Month globally

PROs have responded to digital piracy with various strategies over the years. Numerous attempts have been made to lock down digital content through the use of digital rights management (DRM) technologies. PROs 
have endeavored to educate the consumer on the appropriate use of digital content. They have presented ethical and legal arguments in the hopes of persuading consumers to pay for content and to respect the terms of use. PROs have lobbied for stricter copyright laws and better enforcement. They have enlisted the assistance of Internet service providers to identify copyright infringement, expose the identities of those involved, and issue takedown notices. Record companies in particular have aggressively and successfully sued or settled with over 30,000 individuals ${ }^{5}$.

Strategic outcomes have been mixed, and no one approach has satisfactorily mitigated the persistent challenges of digital piracy. PROs have responded by developing new business models and value propositions that attempt to address evolving consumer tastes and preferences. Some early indications suggest that a few of these efforts may be paying off. As illustrated in Figures 3-5, consumers have increasingly embraced music streaming, which has become an important revenue source for companies.

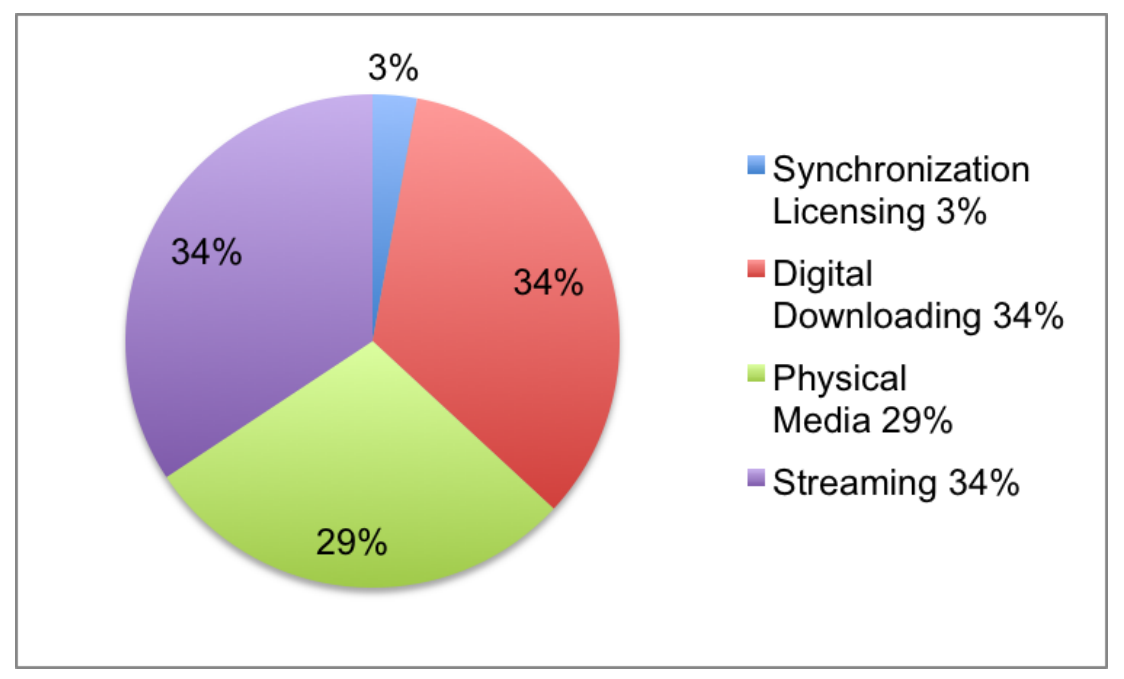

Source: Recording Indusry Association of America ${ }^{6}$

Figure 3. Music industry revenue from multiple sources, U.S. market in 2015 


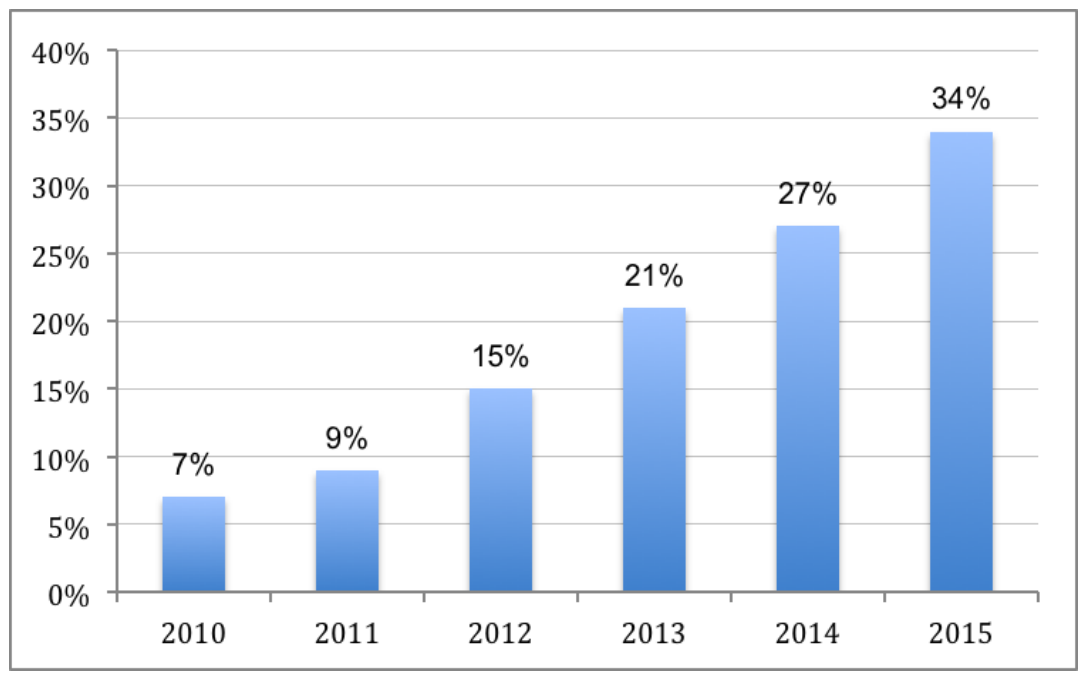

Source: Recording Indusry Association of America ${ }^{6}$

Figure 4. Music industry revenue growth from streaming, U.S. market

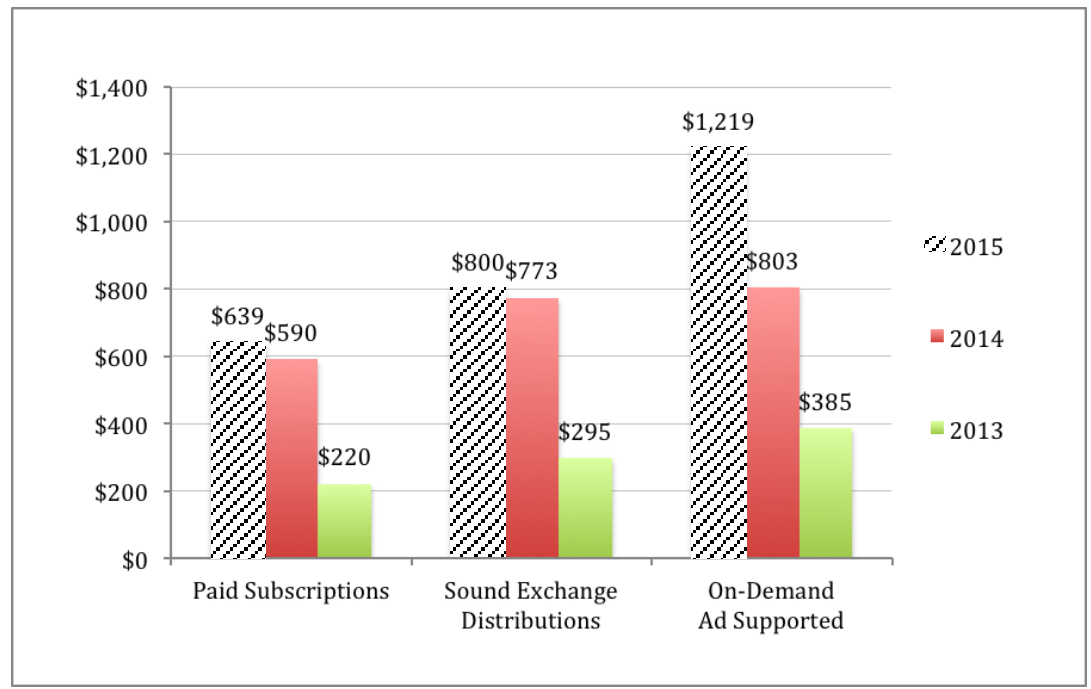

Source: Recording Indusry Association of America ${ }^{6}$

Figure 5. Music industry revenue from various streaming sources in the U.S. market (dollar figures shown in millions)

The NPD Group, which is a marketing research firm, found that the volume of illegally downloaded music files from P2P file-sharing services, one form of digital piracy, declined by 26 percent between 2011 and 2012, which may have been the result of increasing availability and adoption of music streaming systems (MSSs) ${ }^{7}$. One recent study suggested that the 
effect of paid streaming services on revenue is a net positive for the music industry ${ }^{8}$. To encourage the continued adoption of MSSs as an alternative to digital piracy, we need to better understand how to make these systems more appealing.

MSSs and digital downloading platforms are essentially information systems with varying sets of attributes that can be designed and programmed with deliberate intention and specificity. Design considerations can focus on system processes, system requirements, product formats, usage restrictions, platform integration, mobility, and interface design. Each of these factors, depending on how they are addressed, contributes to overall usability and enjoyment for the consumer. Some platforms, such as Apple iTunes, focus on downloadable file objects in contrast to services, such as Rhapsody and Spotify, which focus on streaming content.

Usage restrictions and features vary among different streaming platforms, affording the consumer a choice of differentiated experiences. Some of the differences can have a significant affect on consumer attitudes and behavior. For example, most MSSs do not offer a downloadable file object that can be remixed or incorporated into multimedia projects, which could drive some consumers to seek other alternatives that can include the unauthorized downloading of MP3s from P2P networks. Furthermore, some MSSs require a relatively steady broadband connection for uninterrupted playback. This might be an issue for consumers who often find themselves out of Wi-Fi or cellular range. This study explored the extent to which the key system characteristics influence MSS adoption and unauthorized downloading, the latter being a form of digital piracy.

Specifically, this study aimed to provide empirical support for the following assertions. (1) A MSS can be viewed as an information system, and its adoption can be explained using an expanded technology acceptance model (TAM) and the information system success model (ISSM). (2) The TAM and the ISSM can also be used to explain some of the factors that influence consumer willingness to engage in digital piracy. (3) Specific attributes that positively influence MSS adoption and negatively influence unauthorized downloading intention include perceived system and information quality, the perceived usefulness and enjoyment of the streaming digital product format, and the perceived usefulness, ease of use, and enjoyment of the MSS.

The rest of this paper is organized as follows. A brief literature review and background section provides the reader with a sense of how this study relates to the existing literature. This is followed by the theoretical development of the research model, a discussion of the research methodology, and a presentation of the research results and analysis. The 
paper concludes with a discussion of the findings, research limitations, and possible future research directions.

\section{LITERATURE REVIEW AND BACKGROUND}

Digital piracy has been examined from different perspectives. Several factors that motivate it have been explored using different theoretical frameworks and research methodologies. Studies have focused on different types of products under different sets of circumstances. The literature is extensive, but because the context and nature of digital piracy continues to evolve, additional research is warranted. The following section offers a brief summary of the literature to place this particular research in its proper context.

\subsection{Criminology Perspective}

Given that it is an illegal activity, it is not surprising that theories used in criminology have been applied to digital piracy research as well, including those focused on deterrence ${ }^{9,10,11,12,13}$ neutralization $^{14}$, selfcontrol $^{15,16,17}$, and social learning ${ }^{18,19}$. From various crime related theories, we know that some of the most important predictive and explanatory factors include observing and interacting for extended periods of time with pirating peers $^{9,15}$, having an innate lack of self-control ${ }^{15,20,21,22}$, prior downloading experience ${ }^{21,23}$, and rationalizing the behavior through the denial of harm and other negative consequences ${ }^{14}$. Several risks are associated with digital piracy, including financial, legal, performance, psychological, or social ${ }^{24}$. However, we know that if the benefits outweigh the risks, some individuals will choose to illegally download, duplicate, or share unauthorized copies of digital content $9,13,25,26$.

\subsection{Moral and Ethical Perspective}

Digital piracy has been examined from both deontological and teleological justice perspectives ${ }^{27}$. It is a function of moral recognition, judgment, intensity, and magnitude of the consequences $28,29,30,31,32$. It is also a function of proximity to those who are harmed by digital piracy ${ }^{26}$. The ideology of freeware, beliefs regarding consumer rights, expectations of reciprocity, and antipiracy norms can sway attitudes towards piracy ${ }^{33}$. Some individuals do not recognize a moral imperative because attributions of harm to artists or record labels do not resonate ${ }^{34}$. In fact, some believe that the music industry has taken advantage of consumers by charging high prices, forcing them to purchase entire CDs instead of individual tracks, producing low quality products, and keeping an unfair portion of the profits 


\subsection{Economic Perspective}

Studies have shown that the economic context in which digital piracy occurs can matter a great deal. For example, digital piracy rates tend to be lower as the importance of the entertainment industry in a given market increases, especially in terms of market size ${ }^{39}$. Consumers seem to make the connection between the importance and health of the entertainment industry and its affect on business activity, employment, and various societal benefits. Benefits can include a vibrant marketplace that fosters creativity and variety. For other consumers, the economic issues are more fundamental and come down to whether the benefits outweigh the costs. Several studies have supported this rational choice and utility perspective ${ }^{25}$, $40,41,42,43$. To the extent that utility drives consumer behavior with respect to legal purchasing behavior and unauthorized downloading, this relationship is moderated by music involvement ${ }^{43}$.

\subsection{Psychological and Social Perspective}

Social, psychological, and behavioral factors have received a substantial amount of attention from researchers. Some studies suggest that certain cultural traits matter. For example, cross cultural differences in moral perception have been noted with respect to digital piracy ${ }^{44}$. Individualistic societies, such as the United States, tend to be associated with lower rates of digital piracy in comparison to more collectivist societies, such as Taiwan ${ }^{39}$.

Several studies have addressed digital piracy using social cognitive theory ${ }^{42,45}$. Others have relied on the theory of reasoned action and planned behavior and showed that all three core components of the model attitudes, perceived behavioral control, and social norms - are relevant and provide a basis to explore a wide range of specific motivating factors related to digital piracy ${ }^{10,32,46,47,48,49,50}$. For example, research has demonstrated that Machiavellianism ${ }^{47}$, antipathy towards music industry ${ }^{32,51}$, high costs and low benefits ${ }^{46}$, self-efficacy ${ }^{50}$, anticipated guilt ${ }^{52}$, and idolatry ${ }^{53}$ influence attitudes towards digital piracy.

\subsection{Technology Perspective}

Technology considerations, such as the quality of infrastructure and access to computers, can also influence attitudes towards adoption and digital piracy. For example, greater bandwidth availability tends to facilitate and encourage unauthorized downloading ${ }^{54}$. Being knowledgeable about computers is also positively linked to digital piracy ${ }^{55}$. In general, surprisingly few studies have addressed the adoption of MSS and its effect on digital piracy, specifically from a perspective that focuses on technology 
attributes. Given that MSSs are essentially information systems, it is appropriate to apply the TAM and the ISSM to this research. The following sections develop these ideas in detail.

\section{THEORETICAL DEVELOPMENT AND RESEARCH MODEL}

\subsection{Usefulness, Ease of Use, and Enjoyment}

The TAM has been applied successfully to the study of a wide range of information technologies. It provides a basis for exploring system attributes that may influence technology adoption. Davis suggested that the intention to use an information technology is a function of two factors - perceived usefulness and perceived ease of use $\mathrm{s}^{56}$. The model was originally applied to the types of utilitarian technologies that would be encountered in the workplace to enhance productivity, such as word processing systems. Heijden recognized, however, that technologies could be categorized as either utilitarian or hedonic systems ${ }^{57}$.

Utilitarian technologies, such as business productivity software, provide instrumental value to the user ${ }^{57}$." The use of these types of systems is motivated by factors external to the interaction between the user and the system itself. Design considerations thus focus on ensuring that the technology can perform a set of tasks in a manner that is efficient and effective. In contrast, the use of hedonic technologies is motivated by the interaction with the technology itself. "Hedonic systems aim to provide selffulfilling value to the user ${ }^{57}$." Users interact with hedonic technologies because they are fun, stimulating, and provide pleasure. Examples of hedonic technologies include gaming and home entertainment systems. When Heijden's version of the extended TAM is applied to hedonic technologies, the construct of perceived enjoyment tends to emerge as a strong predictor of technology acceptance ${ }^{57}$. A MSS has both utilitarian and hedonic characteristics; therefore, it is appropriate to apply Heijden's version of the TAM.

From a practical perspective, a useful MSS can support various phases of the consumer buying lifecycle, including needs awareness, product interest, consideration of alternatives, purchasing decision, customer support, repeat purchases, and referral. MSSs offer various means to search and organize content, sift through rankings and commentary, find new music, access product information, and facilitate legitimate content sharing. MSSs that are useful should attract consumers and discourage the adoption of unauthorized alternatives. For the purposes of this research, perceived MSS usefulness was adapted from Heijden's research and defined as the 
extent to which a person believes that a MSS would enhance his or her ability to consume music ${ }^{57,58}$.

H1: Perceived MSS usefulness is negatively related to unauthorized downloading intention.

H2: Perceived MSS usefulness is positively related to MSS purchasing intention.

The consumption of music allows individuals "to regulate arousal and mood, to achieve self-awareness, and as an expression of social relatedness 59 ." Recommendation algorithms and good browsing tools allow users to derive enjoyment from the discovery of new music. Users can experience the enjoyment of creative expression through developing and sharing playlists. MSSs that are enjoyable should attract consumers and discourage the adoption of unauthorized alternatives. For the purposes of this research, perceived MSS enjoyment was adapted from Heijden's research and defined as the extent to which the act of using a MSS is perceived to be enjoyable in its own right separate from any performance considerations ${ }^{57,58}$.

H3: Perceived MSS enjoyment is negatively related to unauthorized downloading intention.

H4: Perceived MSS enjoyment is positively related to MSS purchasing intention.

For a system to be enjoyable and useful, it should be easy to use. The lack of easy to use systems for accessing legitimate products in a desired format, free of tight usage restrictions, could motivate individuals to seek unauthorized alternatives. The MP3 file format and a wide selection of MP3 player devices had been available for years, but when Apple launched the iTunes platform, it introduced the consumer to a significantly easier, more seamless and hassle free way to acquire and consume music. Consumers could more easily locate, retrieve, organize, and consume music and other types of audio products, such as podcasts. The Apple iTunes environment was perceived to be a leap in quality and usability, and as a result, achieved commercial success.

Notwithstanding its success, some consumers resisted the DRM technology that Apple used to control the music product terms of use. Many found it to be cumbersome. Apple FairPlay was used to control access to content and restrict the ability to share with others. Consumers were also restricted to the Apple platform. By eventually eliminating FairPlay for songs purchased and downloaded from iTunes store, Apple made the platform easier to use and thus more appealing. In general, we can expect this to be the case for any platform. An easy to use MSS should attract consumers and at the same time discourage the adoption of unauthorized 
alternatives. For the purposes of this research, perceived MSS ease of use was adapted from Heijden's research and defined as the degree to which a person believes that using a MSS would be free from effort ${ }^{57,58}$.

H5: Perceived MSS ease of use is positively related to MSS usefulness.

H6: Perceived MSS ease of use is positively related to MSS enjoyment.

Music product usage restrictions can be defined in ways that lead to different tradeoffs for the consumer. Object encoding can facilitate or impede the ability of users to consume, share, edit, or remix digital content. As previously mentioned, Apple FairPlay was used to encode songs downloaded from the Apple Store and this significantly circumscribed the ways in which consumers could enjoy their products. They still use it to manage Apple Music streams for offline consumption. However, other file characteristics, such as size and compression, can affect usefulness and enjoyment as well.

For example, some file formats entail heavy compression in order to facilitate streaming; however, this tends to reduce fidelity, and it could amount to an unacceptable compromise in sound quality for music enthusiasts. Uncompressed file formats retain the highest level of sound quality, but the larger file sizes could diminish suitability for Internet transmission and mobile consumption, especially over heavily congested networks. File characteristics can also affect how difficult it might be to repurpose or manipulate content.

The usage restrictions associated with a product format could determine the overall perceived usefulness and enjoyment of a MSS. A circumscribed set of restrictions could encourage consumers to seek alternatives. Based on Heijden's research, we can define two constructs. Perceived product format usefulness is defined as the degree to which a person believes that using a particular product format enhances his or her ability to consume music ${ }^{57,58}$. Perceived product format enjoyment is defined as the extent to which using a particular product format is perceived to be enjoyable in its own right separate from any performance considerations ${ }^{57,58}$.

H7: Perceived product format usefulness is positively related to MSS usefulness.

H8: Perceived product format enjoyment is positively related to MSS purchasing intention. 


\subsection{Perceived Quality}

Perceived quality can be defined in different ways, depending on the context. It can refer to product or service characteristics, features, or properties. Product characteristics can reflect a certain grade of excellence or degree of superiority relative to other products and services. Perceived quality can refer to the range and variety of features attached to a product or service. Perceived quality can refer to the properties of a product or service that make it unique. Perceived quality can be defined as a belief that a system meets or exceeds the user's expectations in ways that are important to the user. Factors that determine the perceived quality of a technology have been examined extensively in the literature. Table 1 below provides an overview of the selected literature and key dimensions that have been used to define the quality of a web site and that are relevant to MSSs.

Table 1. Selected literature regarding website quality

\begin{tabular}{|c|c|}
\hline Authors & Key Quality Dimensions \\
\hline Cox and Dale ${ }^{60}$ & $\begin{array}{l}\text { Accessibility, communication, credibility, understanding the } \\
\text { customer, appearance, availability }\end{array}$ \\
\hline Yoo and Donthu ${ }^{61}$ & $\begin{array}{l}\text { Ease of use, aesthetic design, processing speed, security, } \\
\text { competitive value, clarity of ordering, corporate and brand } \\
\text { equity, product uniqueness, product quality assurance }\end{array}$ \\
\hline $\begin{array}{l}\text { Loiacono, Watson, and } \\
\text { Goodhue }{ }^{62}\end{array}$ & $\begin{array}{l}\text { Ease of understanding, intuitive operations, information } \\
\text { quality, fit-to-task, tailored communications, trust, response } \\
\text { time, visual appeal, innovativeness, emotional appeal, on-line } \\
\text { completeness, relative advantage, consistent image }\end{array}$ \\
\hline Yang and Jun ${ }^{63}$ & $\begin{array}{l}\text { Reliability, access, ease of use, personalization, security, } \\
\text { credibility }\end{array}$ \\
\hline Madu and Madu ${ }^{64}$ & $\begin{array}{l}\text { Performance, features, structure, aesthetics, reliability, storage } \\
\text { capability, serviceability, security and system integrity, trust, } \\
\text { responsiveness, product/service differentiation, web store } \\
\text { policies, reputation, knowledgeable \& courteous employees, } \\
\text { empathy }\end{array}$ \\
\hline Zeithaml $^{65}$ & $\begin{array}{l}\text { Efficiency, fulfillment, reliability, privacy, responsiveness, } \\
\text { compensation, contact }\end{array}$ \\
\hline Santos $^{66}$ & $\begin{array}{l}\text { Ease of use, appearance, linkage, structure and layout, } \\
\text { content, reliability, efficiency, support, communications, } \\
\text { security, incentives }\end{array}$ \\
\hline
\end{tabular}


Table 1. Selected literature regarding website quality (Cont.)

\begin{tabular}{|c|c|}
\hline Authors & Key Quality Dimensions \\
\hline Wolfinbarger and Gilly ${ }^{67}$ & $\begin{array}{l}\text { Website design, fulfillment/reliability, privacy/security, } \\
\text { customer service }\end{array}$ \\
\hline Yang, Peterson, and Cai ${ }^{68}$ & $\begin{array}{l}\text { Responsiveness, credibility, ease of use, reliability, } \\
\text { convenience, communication, access, competence, courtesy, } \\
\text { personalization, continuous improvement, internal } \\
\text { collaboration, security/privacy, aesthetics }\end{array}$ \\
\hline Kim and Stoel ${ }^{69}$ & $\begin{array}{l}\text { Web appearance, entertainment, informational fit-to-task, } \\
\text { transaction capability, response time, trust }\end{array}$ \\
\hline Yang, Jun and Peterson ${ }^{70}$ & $\begin{array}{l}\text { Reliability, responsiveness, competence, ease of use, product } \\
\text { portfolio, security }\end{array}$ \\
\hline Yang and Fang ${ }^{71}$ & $\begin{array}{l}\text { Responsiveness, service reliability, ease of use, competence, } \\
\text { access, system reliability, timeliness, security, courtesy, } \\
\text { service portfolio, continuous improvement, communication, } \\
\text { aesthetic, credibility, system flexibility }\end{array}$ \\
\hline $\begin{array}{l}\text { Gounaris, Dimitriadis, and } \\
\text { Stathakopoulos }\end{array}$ & $\begin{array}{l}\text { Information, user friendliness, interaction/adaptation, } \\
\text { aesthetics }\end{array}$ \\
\hline Lee and $\operatorname{Lin}^{73}$ & $\begin{array}{l}\text { Website design, reliability, responsiveness, trust, } \\
\text { personalization, overall service quality }\end{array}$ \\
\hline $\begin{array}{l}\text { Plarasurman, Zeithaml, } \\
\text { and Malhotra }\end{array}$ & $\begin{array}{l}\text { Efficiency, fulfillment, system availability, privacy, } \\
\text { responsiveness, compensation, contact }\end{array}$ \\
\hline Fassnacht and Koese ${ }^{75}$ & $\begin{array}{l}\text { Graphic quality, clarity of layout, attractiveness of selection, } \\
\text { information quality, ease of use, technical quality, reliability, } \\
\text { functional benefit, emotional benefit }\end{array}$ \\
\hline Kim, Kim, and Lennon ${ }^{76}$ & $\begin{array}{l}\text { Efficiency, fulfillment, system availability, privacy, } \\
\text { responsiveness, contact personalization, information, graphic } \\
\text { style }\end{array}$ \\
\hline Ahn, Ryu, and $\operatorname{Han}^{77}$ & System quality, Information quality, Service quality \\
\hline $\begin{array}{l}\text { Cristobal, Flavián, and } \\
\text { Guinalíu }^{78}\end{array}$ & Web design, customer service, assurance, order management \\
\hline Sohn and Tadisina ${ }^{79}$ & $\begin{array}{l}\text { Trust, customized communication, ease of use, availability, } \\
\text { appropriateness of webpage content, multi-functional } \\
\text { websites }\end{array}$ \\
\hline
\end{tabular}


Table 1. Selected literature regarding website quality (Cont.)

\begin{tabular}{|c|c|}
\hline Authors & Key Quality Dimensions \\
\hline $\mathrm{Li}$ and Suomi ${ }^{80}$ & $\begin{array}{l}\text { Website design, reliability, fulfillment, security, } \\
\text { responsiveness, personalization, information, empathy }\end{array}$ \\
\hline Rao and $\mathrm{Rao}^{81}$ & Efficiency, system availability, fulfillment, privacy \\
\hline $\begin{array}{l}\text { Xu, Benbasat, and } \\
\text { Cenfetelli }^{82}\end{array}$ & $\begin{array}{l}\text { Information satisfaction, information quality, completeness, } \\
\text { accuracy, format, currency, system satisfaction, system } \\
\text { quality, reliability, flexibility, accessibility, timeliness, service } \\
\text { satisfaction, service quality, tangibles, responsiveness, } \\
\text { empathy, service reliability, assurance }\end{array}$ \\
\hline Ellahi and Bokhari ${ }^{83}$ & $\begin{array}{l}\text { User friendly, navigation, efficiency, entertainment, } \\
\text { appearance, privacy/security, community driven }\end{array}$ \\
\hline $\mathrm{Cebi}^{84}$ & $\begin{array}{l}\text { Usability, visual aspects, technical adequacy, security, } \\
\text { communication, prestige }\end{array}$ \\
\hline $\begin{array}{l}\text { Bressolles, Durrieu, and } \\
\text { Senecal }^{85}\end{array}$ & $\begin{array}{l}\text { Information (quality \& quantity), ease of use, aesthetics, } \\
\text { security \& privacy }\end{array}$ \\
\hline $\begin{array}{l}\text { Al-Qeisi, Dennis, } \\
\text { Alamanos, and } \\
\text { Jayawardhena }^{86}\end{array}$ & $\begin{array}{l}\text { Technical quality, general content quality, special content } \\
\text { quality, appearance quality }\end{array}$ \\
\hline $\begin{array}{l}\text { Gonzalez, Quesada, } \\
\text { Davis, and Mora-Monge }\end{array}$ & $\begin{array}{l}\text { Usefulness, ease of use, entertainment, complementary } \\
\text { relationship }\end{array}$ \\
\hline $\begin{array}{l}\text { Blut, Chowdhry, Mittal, } \\
\text { and Brock } \\
8\end{array}$ & Website design, fulfillment, customer service, security \\
\hline
\end{tabular}

We can observe that certain factors that define quality tend to emerge with more frequency. These factors include the following.

- Accessibility ${ }^{60,63,71}$

- Aesthetics ${ }^{61,64,68}$

- Availability 60,74

- Courtesy 68,71

- Credibility ${ }^{60,68,71}$

- Customer service ${ }^{67,78}$

- Communication $60,71,79$

- Design quality ${ }^{67,72,73}$

- Efficiency ${ }^{74,76}$

- Fulfillment $^{74,76}$
- Information quality $69,71,72,75,76$

- Interactivity ${ }^{62}$

- Personalization and customization $63,68,73,79$

- Privacy ${ }^{74,76}$

- Reliability ${ }^{71,73,75,79}$

- Responsiveness ${ }^{71,72,73,74,76}$

- Security $67,70,88$

- Trust $^{72,73,79}$ 
The listed factors relate to perceived service quality, perceived system quality, and perceived information quality, all of which have been described by the information systems success model ${ }^{89}$. For the purposes of this research, the focus was on system and information quality.

System quality is defined by factors, such as appearance, technical adequacy, latency, ease of navigation, security, and privacy ${ }^{77}$. Information quality concerns issues regarding accuracy, completeness, timeliness, and reliability ${ }^{77}$. Platforms, such as Apple iTunes, Amazon, Rhapsody, Netflix, and other successful streaming and downloading services, provide easy access to information regarding content, copyright, authorship, background, related works, reviews, and ratings. We can expect that consumers will be attracted to systems that offer a quality experience that matches or exceeds what they have come to expect from traditional music products and services. Both system and information quality contribute to the consumers' convenience and satisfaction, which makes a MSS easier to use.

H9: Perceived system quality is positively related to perceived MSS ease of use.

H10: Perceived information quality is positively related to perceived MSS ease of use.

\subsection{General Attitude toward Unauthorized Downloading}

Consumers can develop a general attitude towards digital piracy that can become fairly stable over time and exist prior to any interaction with a MSS. We know that general attitude towards digital piracy varies among individuals. It can be affected by cognitive and affective beliefs about the behavior and its perceived importance ${ }^{47}$. A positive attitude can result from previous satisfactory experiences. It can result from perceived benefits of digital piracy, such as the ability to easily discover and share new music. The discovery of new music can inspire creativity, evoke positive emotions, and facilitate mood management. The sharing of music can foster a sense of community among friends and family.

Consumers may develop generally positive attitudes towards digital piracy by avoiding negative consequences and being led to believe that it is a low risk activity. Although more than 30,000 lawsuits have been filed against individuals who have illegally downloaded content in the United States, this represents a small fraction of the total population of illegal downloaders ${ }^{5}$. Digital piracy can have less serious downsides as well. For example, it can be time-consuming to find specific content in a desired format. 
General attitude towards digital piracy can also be affected by habits and norms, which can result from being immersed in an environment in which digital piracy is common and socially accepted. As noted earlier, social learning theory suggests that individuals often develop their notions of acceptable behavior by observing others. Individuals can then become comfortable with a certain behavior, and they may use their preferred methods to develop their skills to continue that behavior. Several studies have shown that habit and past positive experiences tend to foster positive attitudes towards digital piracy ${ }^{24,90,91}$.

H11: General attitude toward unauthorized downloading is positively related to downloading intention.

\subsection{Perceived Cost of the Product}

Numerous studies have found that perceived cost is an important factor that influences unauthorized downloading intention. As the price of a digital product goes up, the willingness to acquire digital products without paying for them tends to go up as well. This may be further influenced by the extent to which the consumer feels that the product is a necessity versus a discretionary purchase. The impact of cost has been very consistent across several studies ${ }^{39,54,92}$. Given the importance and consistency of this factor, cost was included in the model for completeness.

H12: Perceived cost is positively related to unauthorized downloading intention.

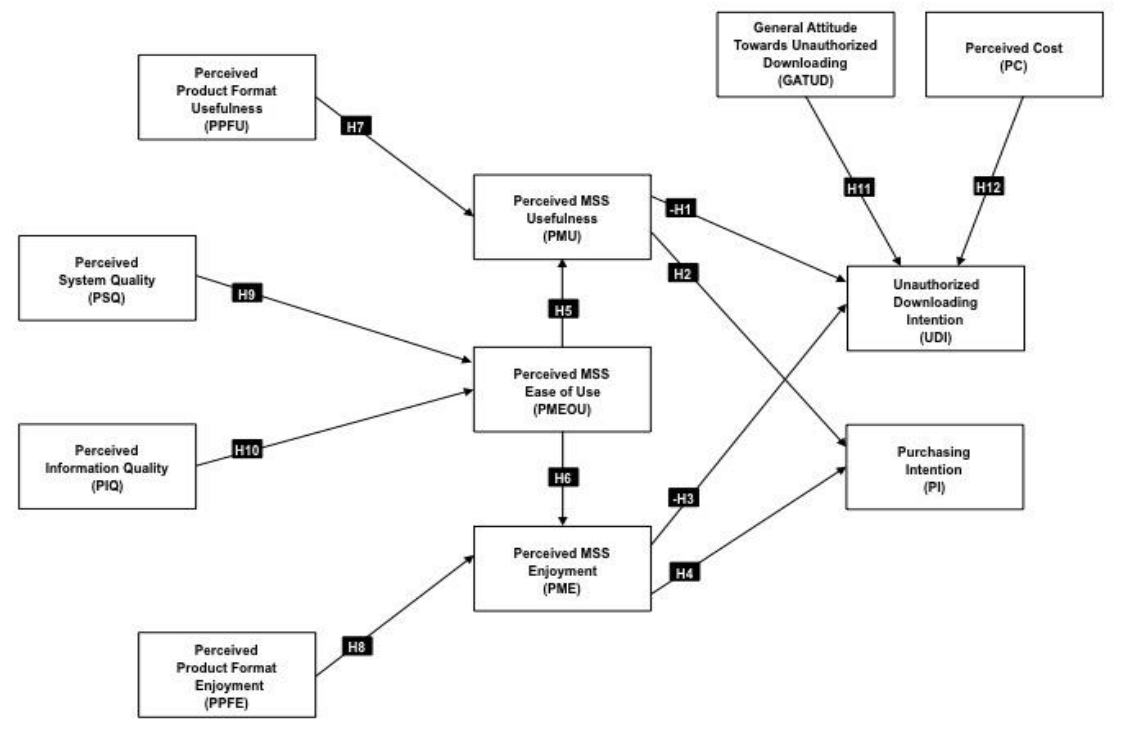

Figure 6. Research model 


\section{METHODOLOGY}

This research used a quasi-experimental methodology. Quasi experiments allow researchers to examine the phenomena in a more natural setting and expose subjects to many different types of cues. Reactions of the test subjects are more likely to be realistic, and this allows for greater generalization of the findings. Quasi experiments are appropriate when the control of independent variables is neither possible nor desirable, or when models are relatively complex. They are often substantially more cost effective and time efficient compared to true experiments. Setting up an experimental MSS for the purposes of this study would have been prohibitively expensive and complex.

In this study, the subjects were asked to interact with a live, fully functioning commercial MSS. The data was collected via an anonymous, self-reported online survey. The research design and analytical approach were modeled after studies that examined the effect of website characteristics on behavior ${ }^{57,93,94,95,96}$. The subjects were screened and assigned to an unfamiliar MSS. They were given a video introduction and a written summary highlighting all of the essential features of the site. Subsequently, they were given an opportunity to familiarize themselves with the MSS on their own by performing specific tasks and by completing a belief elicitation task in the form of a shopping scenario. They were asked to imagine having to find, sample, and select appropriate music from a small catalog of unfamiliar music that could be added to a playlist for a friend's birthday party. The music would be used to create a slideshow presenting the events in their friend's life.

The subjects were told that while creating these projects, material would be collected, possibly edited or remixed, arranged, and subsequently shared with others. They were told that the projects could be completed using their preferred software. Furthermore, they were told that the music was available for purchase only through their assigned MSS or P2P filesharing networks. After completing the shopping task, subjects were asked about their experience with the site. The measures used were generally adopted from previous studies and modified for the specific context of this study. The subjects were also asked specific questions about their assigned MSS, which required them to peruse the site to provide an answer.

The MSSs used in this study were Grooveshark and Rhapsody. Their business models were consistent with the goals of the study in that both sites were representative of MSSs and allowed for an evaluation of the theoretical model that could be generalized. Each site employed contrasting design aesthetics and implemented specific features in different ways. Consumers could browse or search for music using various criteria. Both 
sites included a personal music library that could be customized, recommendation tools, browser and app-based music players, and allowed their users to create playlists and share music with others. Consumers could tag favorite music and review their listening history. The MSSs allowed consumers to create a personalized listening experience. The Grooveshark interface used a minimalist design in comparison to Rhapsody, the latter of which included additional content, such as music blogs, band history, news, artist features, and charting information. At the time of data collection, Grooveshark offered music in the form of streaming content exclusively whereas Rhapsody offered both streaming and downloadable content for offline consumption. Both sites generated revenues through advertising and subscriptions. Rhapsody additionally generated revenues through a sister site that allowed consumers to purchase MP3 downloads.

The subject pool was a convenience sample of undergraduate students at a large northeastern urban commuter college. For the purposes of this study, the sample pool was deemed appropriate because college students tend to have experience in acquiring digital products online, both legally and as unauthorized downloads ${ }^{47}$. The subjects were screened to verify that they personally had access to computers that they controlled and that they could freely select different ways to acquire music online. Subjects were included in the study if they had engaged in any form of file sharing in the past, legal or otherwise. Subjects were assigned to unfamiliar MSSs to shop for unfamiliar music in order to reduce the effects of prior experience and to encourage an exploration of the assigned MSS.

\section{ANALYSIS AND RESULTS}

Partial least squares structural equation modeling (PLS-SEM) was used to analyze the data. The procedure has certain advantages over other methods. It does not have strict normality requirements, which gives the researcher some flexibility with respect to the data set ${ }^{97,98,99}$. The technique is well suited for testing complex relationships, since it avoids inadmissible solutions and factor indeterminacy that can result from models with large numbers of variables, relationships, and moderating effects ${ }^{94}$. An important advantage of PLS-SEM is that the sample size requirements are relatively small, allowing the investigator to economize on time and expense. To determine the minimum required sample size, a rule of thumb is to consider the latent construct with the most causal relationships and the indicator block with the largest number of indicators. The larger number multiplied by ten determines the minimum sample size ${ }^{98}$. In this study, unauthorized downloading intention was the latent construct with the greatest number of causal relationships, specifically four causal relationships. The indicator block associated with perceived product format usefulness had the largest 
number of indicators, which totaled seven. As a result, the required minimum number of samples was 70 . This study included 139 cases, which comfortably exceeds the minimum required sample size.

The sample size of 139 subjects was almost evenly split between men and women at $49 \%$ and $51 \%$, respectively. Based on the self-reporting of the participants in this study, $45 \%$ indicated that they have acquired authorized music online from sources such as Amazon and Apple iTunes in the past. Furthermore, $89 \%$ reported having engaged in unauthorized downloading. The median age of the participants was 21 years. Harman's one factor test 100 did not indicate the presence of common methods bias, which may occur in self-reported surveys. This was further supported by the correlation matrix, which did not exhibit high correlations among constructs ( $r$ value $>$ $0.90)^{94}$.

\subsection{Measurement Model Assessment}

Item reliability and internal consistency were assessed according to the common practice ${ }^{97,98,99}$. After an initial analysis, six measurement items were dropped because of low loading on their respective factors or because they loaded more on factors other than the ones they were intended to measure. The items excluded from further analysis were PIQ3, PIQ4, PSQ4, PSQ7, PPFU4, and PMUA1. The results from the subsequent analysis were reasonably good. As noted in Table 4, each item loaded highly on its latent construct. Each item had significant t-values. As indicated in Table 3, the AVE exceeded 0.50 for all constructs, which supports the convergent validity of the constructs. Cronbach's alpha was well above the generally recommended value of 0.70 for most constructs. The composite reliability statistic demonstrated good item reliability, since every statistic was above the generally recommended value of 0.70 .

Discriminant validity of the construct measures was also assessed according to the common practice $97,98,99$ and was found to be satisfactory. As noted in Table 2, the square root of the AVE associated with each construct was greater than the correlations among constructs, indicating that the construct shares more variance with its own measures. In addition, as noted in Table 4, no item loaded higher on other latent constructs than on the construct it was designed to measure. Discriminant validity was further supported by the fact that the correlations among all constructs were below the threshold of 0.90 .

\subsection{Structural Model Assessment}

As illustrated in Figure 7, the data largely supported the model, with the exception of hypothesis H3. Perceived MSS usefulness was found to have a negative relationship with unauthorized downloading intention and a 
positive relationship purchasing intention $(\beta=-0.207, p<0.01$, and $\beta=$ $0.312, p<0.01$, respectively). The relationship between perceived MSS enjoyment and unauthorized downloading intention was not supported; however, a substantial and significant relationship between perceived MSS enjoyment and purchasing intention was supported $(\beta=0.420, p<0.01)$. Perceived MSS ease of use was positively linked to perceived MSS usefulness and perceived MSS enjoyment $(\beta=0.201, p<0.01$ and $\beta=$ $0.268, p<0.01$, respectively). Perceived product format usefulness was positively linked to perceived MSS usefulness $(\beta=0.603, p<0.01)$. Perceived service quality and perceived information quality were both positively linked to perceived MSS ease of use $(\beta=0.330, p<0.01$, and $\beta=$ $0.501, p<0.01$, respectively). Perceived product format enjoyment was positively linked to perceived MSS enjoyment $(\beta=0.574, p<0.01)$. Finally, both attitude toward unauthorized downloading intention and perceived cost were positively linked unauthorized downloading intention $(\beta=0.645, p<$ 0.01 , and $\beta=0.197, p<0.01$, respectively). Overall, the model explained more than $51 \%$ of the variation in unauthorized downloading intention and just over $43 \%$ of the variation in purchasing intention.

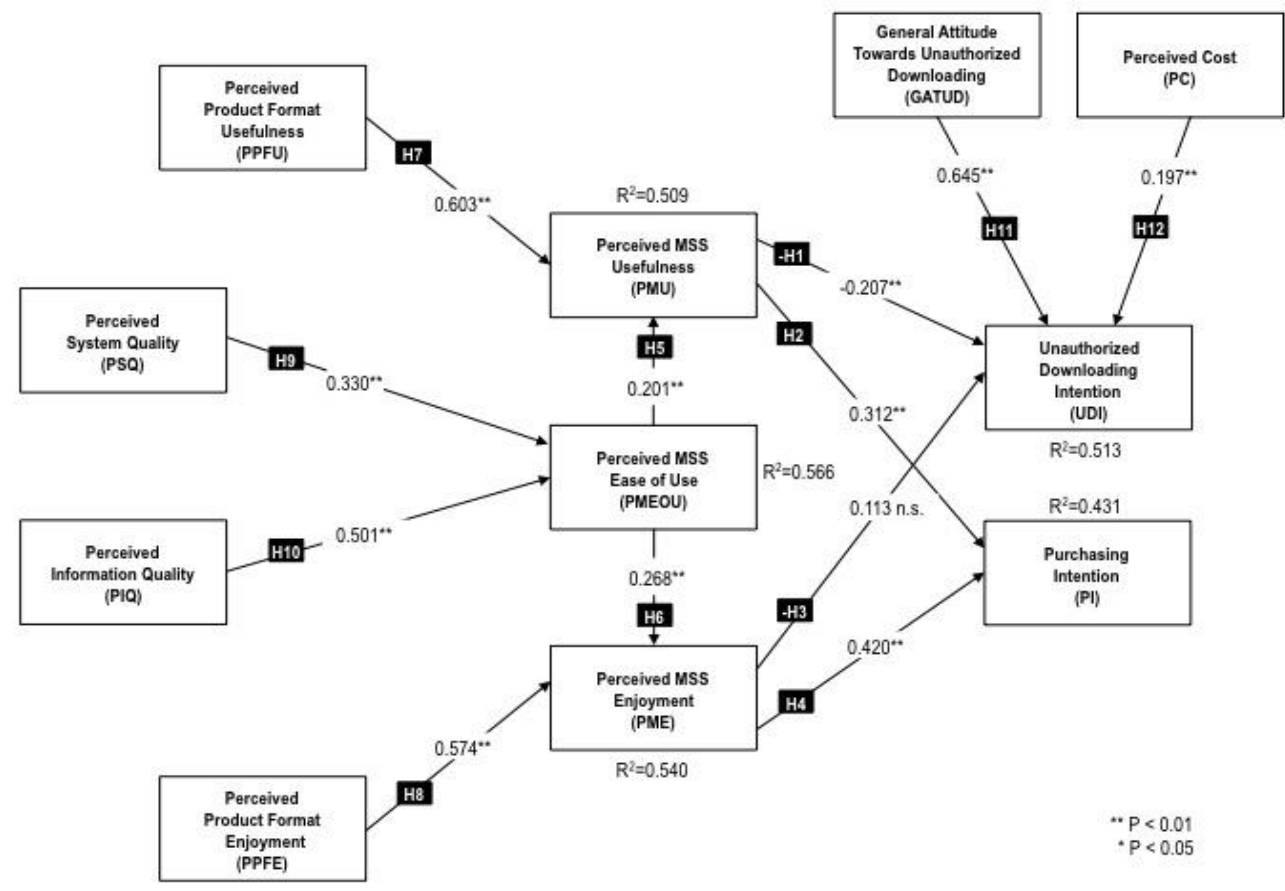

Figure 7. PLS research results 
Table 2. Construct correlations (Square root AVE in bold)

\begin{tabular}{cccccccccccc}
\hline & ATUD & PC & PI & PIQ & PME & PMEOU & PMU & PPFE & PPFU & PSQ & UDI \\
\hline GATUD & 0.888 & & & & & & & & & & \\
PC & 0.173 & 0.736 & & & & & & & & & \\
PI & -0.204 & -0.232 & 1.000 & & & & & & & & \\
PIQ & -0.016 & -0.222 & 0.481 & 0.720 & & & & & & & \\
PME & -0.271 & -0.341 & 0.606 & 0.616 & 0.814 & & & & & & \\
PMEOU & 0.048 & -0.177 & 0.279 & 0.659 & 0.502 & 0.750 & & & & & \\
PMU & -0.117 & -0.116 & 0.563 & 0.572 & 0.596 & 0.376 & 0.774 & & & & \\
PPFE & -0.262 & -0.205 & 0.458 & 0.590 & 0.695 & 0.419 & 0.501 & 0.791 & & & \\
PPFU & -0.204 & -0.176 & 0.506 & 0.525 & 0.609 & 0.372 & 0.690 & 0.716 & 0.798 & & \\
PSQ & -0.020 & -0.203 & 0.376 & 0.624 & 0.678 & 0.670 & 0.507 & 0.541 & 0.537 & 0.713 & \\
UDI & 0.673 & 0.295 & -0.224 & -0.103 & -0.252 & 0.001 & -0.238 & -0.300 & -0.326 & 0.002 & 0.830 \\
\hline
\end{tabular}

Table 3. Assessment of measurement model

\begin{tabular}{ccccccc}
\hline & AVE & $\begin{array}{c}\text { Composite } \\
\text { Reliability }\end{array}$ & $\begin{array}{c}\text { R } \\
\text { Square }\end{array}$ & $\begin{array}{c}\text { Cronbach's } \\
\text { Alpha }\end{array}$ & Mean & SD \\
\hline GATUD & 0.789 & 0.949 & & 0.933 & 4.529 & 1.548 \\
PC & 0.542 & 0.774 & & 0.724 & 3.807 & 1.312 \\
PI & 1.000 & 1.000 & 0.431 & 1.000 & 4.144 & 1.958 \\
PIQ & 0.519 & 0.809 & & 0.691 & 5.193 & 0.975 \\
PME & 0.662 & 0.921 & 0.540 & 0.897 & 5.168 & 1.226 \\
PMEOU & 0.563 & 0.863 & 0.566 & 0.806 & 5.629 & 1.002 \\
PMU & 0.600 & 0.857 & 0.509 & 0.776 & 4.629 & 1.228 \\
PPFE & 0.626 & 0.909 & & 0.881 & 4.829 & 1.247 \\
PPFU & 0.636 & 0.913 & & 0.886 & 4.629 & 1.267 \\
PSQ & 0.508 & 0.834 & & 0.752 & 5.407 & 0.955 \\
UDI & 0.689 & 0.869 & 0.513 & 0.774 & 4.572 & 1.665 \\
\hline
\end{tabular}


Table 4. Cross loadings

\begin{tabular}{|c|c|c|c|c|c|c|c|c|c|c|c|}
\hline & ATUD & $\mathbf{P C}$ & PI & PIQ & PME & PMEOU & PMU & PPFE & PPFU & PSQ & UDI \\
\hline GATUD1 & 0.926 & 0.180 & -0.169 & 0.009 & -0.250 & 0.092 & -0.073 & -0.245 & -0.193 & -0.007 & 0.641 \\
\hline GATUD2 & 0.906 & 0.195 & -0.159 & -0.003 & -0.230 & 0.073 & -0.104 & -0.236 & -0.158 & 0.002 & 0.626 \\
\hline GATUD3 & 0.847 & 0.141 & -0.224 & 0.001 & -0.241 & 0.029 & -0.061 & -0.223 & -0.155 & -0.043 & 0.549 \\
\hline GATUD4 & 0.849 & 0.133 & -0.186 & -0.077 & -0.240 & -0.052 & -0.149 & -0.278 & -0.218 & -0.017 & 0.509 \\
\hline GATUD5 & 0.909 & 0.118 & -0.178 & -0.012 & -0.245 & 0.052 & -0.136 & -0.194 & -0.190 & -0.027 & 0.645 \\
\hline PC1 & 0.094 & 0.645 & -0.203 & -0.190 & -0.192 & -0.254 & -0.103 & -0.214 & -0.213 & -0.213 & 0.128 \\
\hline PC2 & 0.026 & 0.601 & -0.116 & -0.088 & -0.144 & -0.035 & 0.001 & -0.101 & -0.126 & -0.133 & 0.108 \\
\hline PC3 & 0.194 & 0.922 & -0.201 & -0.201 & -0.346 & -0.132 & -0.120 & -0.163 & -0.116 & -0.151 & 0.320 \\
\hline PI & -0.204 & -0.232 & 1.000 & 0.481 & 0.606 & 0.279 & 0.563 & 0.458 & 0.506 & 0.376 & -0.224 \\
\hline PIQ1 & 0.030 & -0.133 & 0.368 & 0.810 & 0.542 & 0.610 & 0.422 & 0.394 & 0.371 & 0.589 & 0.001 \\
\hline PIQ2 & -0.083 & -0.169 & 0.352 & 0.627 & 0.382 & 0.323 & 0.404 & 0.433 & 0.325 & 0.262 & -0.175 \\
\hline PIQ5 & 0.046 & -0.123 & 0.411 & 0.819 & 0.481 & 0.524 & 0.542 & 0.494 & 0.541 & 0.540 & -0.043 \\
\hline PIQ6 & -0.101 & -0.266 & 0.253 & 0.596 & 0.332 & 0.369 & 0.266 & 0.421 & 0.249 & 0.304 & -0.163 \\
\hline PME1 & -0.210 & -0.299 & 0.558 & 0.585 & 0.850 & 0.535 & 0.534 & 0.606 & 0.570 & 0.694 & -0.228 \\
\hline PME2 & -0.247 & -0.209 & 0.576 & 0.471 & 0.821 & 0.316 & 0.541 & 0.586 & 525 & 0.439 & -0.316 \\
\hline PME3 & -0.193 & -0.370 & 0.426 & 0.429 & 0.727 & 0.388 & 0.358 & 0.510 & 388 & 0.482 & -0.111 \\
\hline PME4 & -0.292 & -0.301 & 0.419 & 0.510 & 0.865 & 0.446 & 0.437 & 0.592 & 483 & 0.574 & -0.240 \\
\hline PME5 & -0.118 & -0.220 & 0.572 & 0.553 & 0.828 & 0.473 & 0.604 & 0.554 & 0.603 & 0.653 & -0.105 \\
\hline PME6 & -0.277 & -0.292 & 0.367 & 0.438 & 0.782 & 0.263 & 0.398 & 0.533 & 0.361 & 0.438 & -0.216 \\
\hline PMEOU1 & 0.062 & -0.154 & 0.277 & 0.490 & 0.397 & 0.766 & 0.299 & 0.368 & 316 & 0.498 & 0.051 \\
\hline PMEOU2 & 0.048 & -0.212 & 0.197 & 0.416 & 0.286 & 0.746 & 0.200 & 0.206 & 183 & 0.457 & 0.038 \\
\hline PMEOU3 & -0.085 & -0.109 & 0.045 & 0.230 & 0.270 & 0.558 & 0.014 & 0.252 & 0.083 & 0.349 & 0.013 \\
\hline PMEOU4 & 0.055 & -0.122 & 0.283 & 0.667 & 0.501 & 0.810 & 0.460 & 0.436 & 0.421 & 0.564 & -0.073 \\
\hline PMEOU5 & 0.045 & -0.091 & 0.168 & 0.531 & 0.367 & 0.837 & 0.273 & 0.260 & 0.268 & 0.596 & 0.008 \\
\hline PMUA2 & -0.178 & -0.159 & 0.480 & 0.346 & 0.448 & 0.221 & 0.716 & 0.343 & 0.414 & 0.338 & -0.276 \\
\hline PMUA3 & -0.077 & -0.045 & 0.438 & 0.389 & 0.478 & 0.161 & 0.830 & 0.416 & 0.571 & 0.413 & -0.162 \\
\hline PMUA4 & -0.005 & -0.136 & 0.434 & 0.570 & 0.485 & 0.518 & 0.769 & 0.390 & 0.583 & 0.509 & -0.129 \\
\hline PMUA5 & -0.114 & -0.019 & 0.394 & 0.451 & 0.433 & 0.243 & 0.779 & 0.400 & 0.558 & 0.296 & -0.179 \\
\hline PPFE1 & -0.136 & -0.063 & 0.395 & 0.587 & 0.514 & 0.428 & 0.537 & 0.838 & 0.699 & 0.450 & -0.215 \\
\hline PPFE2 & -0.222 & -0.096 & 0.433 & 0.448 & 0.533 & 0.219 & 0.519 & 0.777 & 0.692 & 0.402 & -0.270 \\
\hline PPFE3 & -0.229 & -0.210 & 0.287 & 0.442 & 0.586 & 0.340 & 0.286 & 0.792 & 0.470 & 0.407 & -0.203 \\
\hline PPFE4 & -0.263 & -0.246 & 0.409 & 0.535 & 0.630 & 0.350 & 0.361 & 0.796 & 0.506 & 0.451 & -0.275 \\
\hline PPFE5 & -0.147 & -0.074 & 0.336 & 0.401 & 0.460 & 0.329 & 0.395 & 0.733 & 0.539 & 0.485 & -0.228 \\
\hline PPFE6 & -0.227 & -0.247 & 0.313 & 0.379 & 0.546 & 0.325 & 0.309 & 0.809 & 0.520 & 0.385 & -0.228 \\
\hline PPFU1 & -0.172 & -0.263 & 0.362 & 0.494 & 0.567 & 0.375 & 0.475 & 0.740 & 0.763 & 0.526 & -0.268 \\
\hline PPFU2 & -0.169 & -0.160 & 0.421 & 0.425 & 0.463 & 0.292 & 0.673 & 0.507 & 0.857 & 0.430 & -0.264 \\
\hline PPFU3 & -0.127 & -0.147 & 0.432 & 0.475 & 0.458 & 0.398 & 0.509 & 0.534 & 0.775 & 0.451 & -0.259 \\
\hline PPFU5 & -0.133 & -0.034 & 0.425 & 0.375 & 0.466 & 0.224 & 0.567 & 0.509 & 0.776 & 0.360 & -0.219 \\
\hline PPFU6 & -0.214 & -0.121 & 0.406 & 0.372 & 0.490 & 0.236 & 0.481 & 0.648 & 0.807 & 0.434 & -0.298 \\
\hline PPFU7 & -0.172 & -0.134 & 0.375 & 0.387 & 0.495 & 0.272 & 0.558 & 0.547 & 0.805 & 0.395 & -0.264 \\
\hline PSQ1 & -0.038 & -0.101 & 0.251 & 0.473 & 0.584 & 0.488 & 0.387 & 0.457 & 0.402 & 0.783 & 0.007 \\
\hline PSQ2 & 0.055 & -0.169 & 0.230 & 0.416 & 0.411 & 0.536 & 0.361 & 0.287 & 0.382 & 0.758 & 0.047 \\
\hline PSQ3 & 0.021 & -0.158 & 0.264 & 0.405 & 0.369 & 0.435 & 0.297 & 0.199 & 0.179 & 0.566 & -0.019 \\
\hline PSQ6 & -0.044 & -0.216 & 0.363 & 0.540 & 0.582 & 0.586 & 0.435 & 0.532 & 0.531 & 0.853 & 0.017 \\
\hline PSQ8 & -0.113 & -0.020 & 0.221 & 0.388 & 0.511 & 0.250 & 0.330 & 0.524 & 0.435 & 0.552 & -0.105 \\
\hline UDI1 & 0.593 & 0.223 & -0.151 & -0.014 & -0.179 & -0.009 & -0.152 & -0.221 & -0.187 & 0.019 & 0.808 \\
\hline UDI2 & 0.539 & 0.283 & -0.172 & -0.105 & -0.184 & 0.039 & -0.190 & -0.244 & -0.240 & 0.081 & 0.850 \\
\hline UDI3 & 0.540 & 0.228 & -0.237 & -0.142 & -0.267 & -0.028 & -0.253 & -0.282 & -0.389 & -0.096 & 0.831 \\
\hline
\end{tabular}




\section{DISCUSSION}

The demand for traditional music media remains substantial, but consumers are becoming increasingly comfortable with just having access to music as streams. The access model of consumption is slowly being adopted for other types of digital products as well, including software, books, movies, and games. The consumption model presents PROs with an opportunity to address high rates of digital piracy. Although MSS adoption is rising at a modest pace, its widespread adoption is not assured ${ }^{101}$. If MSSs are to become the dominant means through which music is sourced, accessed, and consumed, PROs have to learn to tailor the value proposition for different types of consumers.

Ultimately, a MSS has to offer a compelling value and provide a great user experience. Consumers have to be convinced that it is a superior alternative to digital piracy. In that regard, several key considerations should be addressed, including system and information quality, perceived MSS usefulness, perceived MSS ease of use, perceived MSS enjoyment, perceived product format usefulness, and perceived product format enjoyment. The results of this study suggest that they are all important determinants of MSS adoption. Furthermore, all of these factors, with the exception of perceived MSS enjoyment and perceived format enjoyment, are important in discouraging unauthorized downloading intention, a form of digital piracy.

It is interesting to note that the enjoyment of a MSS is not enough to discourage digital piracy. Consumers might be willing to pay for a MSS that is fun to use, but that alone will not discourage digital piracy. It appears that emphasizing the practical aspects of a MSS, such as making it easier to acquire music, is what matters.

The results of this study also show that an easy to use MSS is determined in part by its quality. Due to the importance of system quality, the PRO should address factors, such system availability, reliability, speed, and product features. Consumers are already accustomed to enjoying their music reliably and on the go by tapping into their personal music libraries and by using personal and highly portable listening devices, such as Apple iPods or mobile phones. We can expect that consumers will want to have that same capability using MSSs. Consumers will want to easily connect to MSSs from any location and at any time, which is possible through the increasing penetration of broadband.

MSSs will also have to offer products and services that exhibit minimal latency issues, have excellent navigation tools, incorporate effective 
recommendation algorithms, include well-organized online music libraries, facilitate search for music, and provide the ability to create playlists. Features should be optimized for the consumer's platform of choice, which can include tablets, smartphones, desktops, and other emerging platforms. The interface design should conform to widely adopted standards, and it should be optimized for easy comprehension and aesthetic appeal. It is important to recognize that perceptions of system quality could evolve over time to include increasing standards for privacy, security, error-free transactions, and improved customer service.

One of the advantages of a MSS is that it can offer the consumer a wealth of information about music and related products and services all in one place. A well-designed system can allow consumers to easily find background information on artists, individual songs and albums, and music labels. It can be a single source for song lyrics, song versions, critiques, artist touring schedules, copyright information, artist influences, and genre information. A MSS can help the consumer find related artists and similar music. If this information is of high quality, it will likely contribute to making a MSS easier to use and generally useful. To establish a high level of information quality requires current, complete, accurate, timely, and reliable information that is communicated in an appropriate easy to understand format. It should perhaps be customized for the individual user. Information should be formatted appropriately for the many different types of devices available to consumers.

The usefulness and enjoyment of a MSS is closely linked to the usefulness and enjoyment of the product format, respectively. The encoding of a product and the mechanism though which the product is delivered to the consumer can determine the usage rights and restrictions that afford the consumer a range of possible product uses and experiences. A particular format may not be convenient for streaming purposes or slideshow presentations, and it may not have sufficient fidelity. A streaming object is subject to connectivity issues and often requires a reliable, high bandwidth connection that is not always available. A MSS may not provide music in a format suitable for offline consumption.

It is worth noting that a brief interaction with a MSS, regardless of the quality or usefulness and enjoyability of the system, may not overcome an individual's willingness to engage in digital piracy. A generally positive attitude towards digital piracy, which usually develops over time, encourages the behavior to a great extent. Furthermore, high costs of products tend to influence whether a consumer chooses to engage in digital piracy. PROs owners have to price their products appropriately. Whereas the price of electronics has declined dramatically over the years, the pricing for 
music has not followed this trend at the same pace ${ }^{102}$.

\section{CONCLUSIONS}

Consumers may need a compelling reason to spend money on digital music products that can often be found online free of charge through unauthorized channels. Digital music files can be easily exchanged on both public and private networks. Easy to use software tools allow consumers to extract MP3 files from YouTube videos. The increasing popularity of cloud storage services allows individuals to easily share entire music collections. Many ways exist to engage in digital piracy. To discourage the unauthorized use of digital content, the answer might be to present consumers with a well-designed, attractively priced MSS. This could be an appealing alternative that might be able to transform some digital pirates into paying customers.

In an effort to understand how MSSs might appeal to broader audiences and to digital pirates in particular, the goals of the research were twofold. The first aim was to assess the factors that lead to MSS adoption, and the second aim was to assess the factors that reduce unauthorized downloading intention. The results of this research demonstrated the following.

1. Perceived MSS usefulness, perceived MSS ease of use, and perceived MSS enjoyment are all positively related to the intention to purchase a MSS subscription.

2. Perceived system quality and perceived information quality are both positively related to perceived MSS ease of use.

3. Perceived product format usefulness and perceived product format enjoyment positively influence perceived MSS usefulness and perceived MSS enjoyment, respectively.

4. Perceived MSS usefulness is positively related to purchasing intention and negatively related to unauthorized downloading intention.

5. Perceived MSS usefulness is negatively related to unauthorized downloading intention.

Given that MSSs can be designed in various ways, these results may provide some guidance for PROs. To attract consumers and dissuade them from engaging in digital piracy, MSSs should perhaps be designed with a wide range of useful features and product formats. MSSs should perhaps supply not just digital streams, but also downloadable files that facilitate the enjoyment of music offline. MSSs could provide accurate, extensive, and timely content that consumers would find useful, such as artist biographies, musical influences, and touring schedules. MSSs could facilitate browsing across many different genres and provide music recommendations. MSSs 
could incorporate tools that enable consumers to develop and easily share playlists. This would in turn increase the consumer enjoyment, lead to creative inspiration, and facilitate community building. MSSs should be fast, reliable, secure, interactive, and generally well designed for the consumer's preferred platform.

\section{LIMITATIONS}

This study has important limitations that should be considered. First, quasi experiments do not offer the degree of internal validity that can be achieved with true experiments. Second, a quasi-experiment examines and measures only reactions and behavioral intentions that are subject to conditions at a particular point in time and not those that evolve over time. Third, this study measured self-reported intention and not actual behavior. The fourth limitation concerns the subject pool. Even though the subject pool used in this study was deemed to be appropriate, caution should be exercised when attempting to generalize the results of this study to all demographic segments.

\section{FUTURE RESEARCH}

It is important to recognize that this study used only two MSSs. To draw stronger conclusions, it would be beneficial to replicate this study using other types of MSSs, since they vary with respect to product offerings, usability, features sets, quality, overall design, and value propositions.

The validity of the research model is an invitation to closely explore the characteristics and features that might make a MSS useful, fun, and easy to use. This study addressed a small number of factors, but there are many others worth exploring. MSSs can be designed to facilitate or impede a wide range of usage rights either by design or as an unintended result. For example, MSSs can be designed to facilitate the time and space shifting of consumption. They can be designed to work on various digital platforms, to facilitate the sharing of music, and to support the creative needs of the consumer. These factors may influence the extent to which a consumer chooses to adopt a MSS instead of engaging in digital piracy. Finally, this research could be replicated using a longitudinal design to assess consumers' behavior over time. 


\section{REFERENCES}

[1] Internet_Archive_Wayback_Machine. The Pirate Bay. Retrieved on September 10, 2016, from: https://web.archive.org/web/ 20160910183007

[2] M. T. Bender and Y. Wang, The impact of digital piracy on music sales: A cross-country analysis. International Social Science Review, 84(3/4), p. 157-170, 2009.

[3] NetNames, NetNames Piracy Analysis: Sizing the Piracy Universe. London: UK, September 2013.

[4] R. Steele. Digital Music News. Retrieved on August 24, 2015, from: http://www.digitalmusicnews.com/2015/07/16/if-you-think-piracy-isdecreasing-you-havent-looked-at-the-data- $2 /$

[5] D. Kravets, File Sharing Lawsuits at a Crossroads, After 5 years of RIAA Litigation. Retrieved on August 24, 2015, from: http://www.wired.com/2008/09/proving-file-sh

[6] J. P. Friedlander, News and Notes on 2015 RIAA Shipment and Revenue Statistics. Retrieved on August 24, 2016, from: http://www.riaa.com/wp-content/uploads/2016/03/RIAA-2015-YearEnd-shipments-memo.pdf

[7] NPD_Group, Music file sharing declined significantly in 2012. Retrieved on June 29, 2013, from https://www.npd.com/wps/portal/ $\mathrm{npd} / \mathrm{us} /$ news/press-releases/the-npd-group-music-file-sharing-declinedsignificantly-in-2012/.

[8] N. Wlömert and D. Papies, On-demand streaming services and music industry revenues-Insights from Spotify's market entry. International Journal of Research in Marketing, 33(2), p 314-327, 2016.

[9] K. J. Shanahan and M. R. Hyman, Motivators and enablers of SCOURing: A study of online piracy in the US and UK. Journal of Business Research, 63(9-10), p 1095-1102, 2010. http://dx.doi.org/ 10.1016/j.jbusres.2009.02.026

[10] N. A. Morton and X. Koufteros, Intention to commit online music piracy and its antecedents: An empirical investigation. Structural Equation Modeling, 15(3), p 491-512, 2008. http://dx.doi.org/ 10.1080/10705510802154331

[11] K. Robertson, L. McNeill, J. Green, and C. Roberts, Illegal Downloading, Ethical Concern, and Illegal Behavior. Springer Science \& Business Media B.V., Report 01674544, 2012. http://dx.doi.org/10.1007/s10551-011-1079-3

[12] S. E. Wolfe, G. E. Higgins, and C. D. Marcum, Deterrence and Digital Piracy: A Preliminary Examination of the Role of Viruses. Social Science Computer Review, 26(3), p 317-333, 2008. http://dx.doi.org/ 


\section{$10.1177 / 0894439307309465$}

[13] L. Zhang, W. W. Smith, and W. C. McDowell, Examining digital piracy: Self-control, punishment, and self-efficacy. Information Resources Management Journal, 22(1), p 24-44, 2009. http://dx.doi.org/10.4018/irmj.2009010102

[14] J. R. Ingram and S. Hinduja, Neutralizing music piracy: An empirical examination. Deviant Behavior, 29(4), p 334-366, 2008. http://dx.doi.org/10.1080/01639620701588131

[15] J. Malin and B. J. Fowers, Adolescent self-control and music and movie piracy. Computers in Human Behavior, 25(3), p 718-722, 2009. http://dx.doi.org/10.1016/j.chb.2008.12.029

[16] G. E. Higgins, S. E. Wolfe, and M. L. Ricketts, Digital piracy: A latent class analysis. Social Science Computer Review, 27(1), p 24-40, 2009. http://dx.doi.org/10.1177/0894439308321350

[17] G. E. Higgins, Digital piracy: An examination of low self-control and motivation using short-term longitudinal data. CyberPsychology \& Behavior, 10(4), p 523-529, 2007. http://dx.doi.org/10.1089/cpb.2007. 9995

[18] Z. Yang and J. Wang, Differential effects of social influence sources on self-reported music piracy. Decision Support Systems, 69, p 70-81, 2015. http://dx.doi.org/10.1016/j.dss.2014.11.007

[19] R. G. Morris and G. E. Higgins, Criminological theory in the digital age: The case of social learning theory and digital piracy. Journal of Criminal Justice, 38(4), p 470-480, 2010.

[20] G. E. Higgins, C. D. Marcum, T. L. Freiburger, and M. L. Ricketts, Examining the role of peer influence and self-control on downloading behavior. Deviant Behavior, 33(5), p 412-423, 2012. http://dx.doi.org/10.1080/01639625.2011.584275

[21] G. E. Higgins, S. E. Wolfe, and C. D. Marcum, Digital piracy: An examination of three measurements of self-control. Deviant Behavior, 29(5), p 440-460, 2008. http://dx.doi.org/10.1080/01639620701598023

[22] C. M. Donner, C. D. Marcum, W. G. Jennings, G. E. Higgins, and J. Banfield, Low self-control and cybercrime: Exploring the utility of the general theory of crime beyond digital piracy. Computers in Human Behavior, 34, p 165-172, 2014. http://dx.doi.org/10.1016/j.chb. 2014.01.040

[23] S. A. Taylor, C. Ishida, and D. W. Wallace, Intention to engage in digital piracy: A conceptual model and empirical test. Journal of Service Research, 11(3), p 246-262, 2009. http://dx.doi.org/10.1177/1094670508328924

[24] A. Nandedkar and V. Midha, It won't happen to me: An assessment of 
optimism bias in music piracy. Computers in Human Behavior, 28, $\mathrm{p}$ 41-48, 2012.

[25] K. Borja, S. Dieringer, and J. Daw, The effect of music streaming services on music piracy among college students. Computers in Human Behavior, 45, p 69-76, 2015. http://dx.doi.org/10. 1016/j.chb.2014.11.088

[26] J.-S. Chiou, G.-y. Huang, and H.-h. Lee, The antecedents of music piracy attitudes and intentions. Journal of Business Ethics, 57(2), p 161-174, 2005/03// 2005. http://dx.doi.org/10.1007/s10551-004-5263-6

[27] C. Yoon, Digital piracy intention: a comparison of theoretical models. Behaviour \& Information Technology, 31(6), p 565-576, 2012. http://dx.doi.org/10.1080/0144929X.2011.602424

[28] M. K. Koklic, I. Vida, D. Bajde, and B. Culiberg, The study of perceived adverse effects of digital piracy and involvement: Insights from adult computer users. Behaviour \& Information Technology, 33(3), p 224-235, 2014. http://dx.doi.org/10.1080/ 0144929X.2012.753552

[29] L. Cesareo and A. Pastore, Consumers' attitude and behavior towards online music piracy and subscription-based services. Journal of Consumer Marketing, 31(6/7), p 515-525, 2014. http://dx.doi.org/10.1108/JCM-07-2014-1070

[30] A. d'Astous, F. Colbert, and D. Montpetit, Music piracy on the web how effective are anti-piracy arguments? Evidence from the theory of planned behaviour. Journal of Consumer Policy, 28(3), p 289-310, 2005.

[31] S. Lysonski and S. Durvasula, Digital piracy of MP3s: Consumer and ethical predispositions. Journal of Consumer Marketing, 25(3), p. 167, 2008. http://dx.doi.org/10.1108/07363760810870662

[32] G. Lalović, S. A. Reardon, I. Vida, and J. Reardon, Consumer decision model of intellectual property theft in emerging markets. Organizations \& Markets in Emerging Economies, 3(1), p 58-74, 2012.

[33] R.-A. Shang, Y.-C. Chen, and P.-C. Chen, Ethical decisions about sharing music files in the $\mathrm{P} 2 \mathrm{P}$ environment. Journal of Business Ethics, 80(2), p. 349-365, 2008. http://dx.doi.org/10.1007/s10551-0079424-2

[34] A. M. Levin, M. C. Datoon, and C. Manolis, Deterring illegal downloading: The effects of threat appeals, past behavior, subjective norms, and attributions of harm. Journal of Consumer Behaviour, 6(23), p 111-122, 2007. http://dx.doi.org/10.1002/cb.211

[35] M. M. Jambon and J. G. Smetana, College students' moral evaluations of illegal music downloading. Journal of Applied Developmental Psychology, 33(1), p 31-39, 2012. http://dx.doi.org/10.1016 
/j.appdev.2011.09.001

[36] J. R. Coyle, S. J. Gould, P. Gupta, and R. Gupta, "To buy or to pirate": The matrix of music consumers' acquisition-mode decision-making. Journal of Business Research, 62(10), p 1031-1037, 2009.

[37] A. M. Levin, M. C. DatoOn, and K. Rhee, Money for nothing and hits for free: The ethics of downloading music from peer-to-peer web sites. Journal of Marketing Theory and Practice, 12(1), p 48-60, 2004. http://dx.doi.org/10.1080/10696679.2004.11658512

[38] T. Wingrove, A. L. Korpas, and V. Weisz, Why were millions of people not obeying the law? Motivational influences on non-compliance with the law in the case of music piracy. Psychology, Crime \& Law, 17(3), p 261-276, 2011.

[39] E.-J. Ki, B.-H. Chang, and H. Khang, Exploring influential factors on music piracy across countries. Journal of Communication, 56(2), $\mathrm{p}$ 406-426, 2006/06//2006.

[40] A. B. Lopes and D. F. Galletta, Consumer perceptions and willingness to pay for intrinsically motivated online content. Journal of Management Information Systems, 23(2), p. 203-231, 2006.

[41] C.-C. Wang, Factors that influence the piracy of DVD/VCD motion pictures. Journal of American Academy of Business, Cambridge, 6(1), p. 231-237, 2005.

[42] R. LaRose and J. Kim, Share, Steal, or Buy? A social cognitive perspective of music downloading. CyberPsychology \& Behavior, 10(2), p 267-277, 2007.

[43] B. Culiberg, K. Koklic, I. Vida, and D. Bajde, Examining the effects of utilities and involvement on intentions to engage in digital piracy. Computers in Human Behavior, 61, p 146-154, 2016.

[44] W. P. Wu and H. L. Yang, A comparative study of college students' ethical perception concerning internet piracy. Quality \& Quantity, 47(1), p 111-120, 2013.

[45] R. S. Jacobs, A. Heuvelman, M. Tan, and O. Peters, Digital movie piracy: A perspective on downloading behavior through social cognitive theory. Computers in Human Behavior, 28, p 958-967, 2012.

[46] T. C. Lin, J. S. C. Hsu, and H. C. Chen, Customer willingness to pay for online music: The role of free mentality. Journal of Electronic Commerce Research, 14(4), p 315-333, 2013.

[47] S. Al-Rafee and T. Cronan, Digital piracy: Factors that influence attitude toward behavior. Journal of Business Ethics, 63(3), p 237 259, 2006.

[48] T. P. Cronan and S. Al-Rafee, Factors that influence the intention to pirate software and media. Journal of Business Ethics,78(4), p 527$545,2008$. 
[49] R. Uribe and C. Martínez, Factores que influencian la piratería de música digital desde Internet en Chile. Estudios de Administración, 16(1), p 1-32, 2009.

[50] R. H. Blake and E. S. Kyper, An investigation of the intention to share media files over peer-to-peer networks. Behaviour \& Information Technology, 32(4), p 410-422, 2013.

[51] D. J. Woolley, The cynical pirate: How cynicism effects music piracy. Academy of Information \& Management Sciences Journal, 13(1), p 31-43, 2010.

[52] X. Wang and S. R. McClung, The immorality of illegal downloading: The role of anticipated guilt and general emotions. Computers in Human Behavior, 28(1), p. 153-159, 2012.

[53] C. C. Wang, C. T. Chen, S. C. Yang, and C. K. Farn, Pirate or buy? The moderating effect of idolatry. Journal of Business Ethics, 90, p 81-93, 2009.

[54] S. Bhattacharjee, R. D. Gopal, and G. L. Sanders, Digital music and online sharing: Software piracy 2.0? Association for Computing Machinery. Communications of the ACM, 46, p. 107-111, 2003.

[55] D. McCorkle, J. Reardon, D. Dalenberg, A. Pryor, and J. Wicks, Purchase or pirate: A model of consumer intellectual property theft. Journal of Marketing Theory and Practice, 20(1), p 73-86, 2012.

[56] F. D. Davis, Perceived usefulness, perceived ease of use, and user acceptance of information technology. MIS Quarterly, 13(3), p 319340, 1989.

[57] H. V. D. Heijden, User acceptance of hedonic information systems. MIS Quarterly, 28(4), p 695-704, 2004.

[58] H. V. D. Heijden, Factors influencing the usage of Websites: The case of a generic portal in The Netherlands. Information \& Management, 40(6), p. 541-549, 2003.

[59] T. Schäfer, P. Sedlmeier, C. Städtler, and D. Huron, The psychological functions of music listening. Frontiers in Psychology, 4, 511, 2013. doi: $10.3389 /$ fpsyg.2013.00511

[60] J. Cox and B. G. Dale, Service quality and e-commerce: An exploratory analysis. Managing Service Quality, 11(2), p. 121-131, 2001. https://doi.org/10.1108/09604520110387257

[61] B. Yoo and N. Donthu, Developing a scale to measure the perceived quality of an Internet shopping site (SITEQUAL). Quarterly Journal of Electronic Commerce, 2(1), p 31-47, 2001.

[62] E. Loiacono, R. Watson, and D. Goodhue, WebQual: A measure of Web site quality. Marketing Theory and Applications, 13, p 37-64, 2002.

[63] Z. Yang and M. Jun, Consumer perception of e-service quality: From Internet purchaser and non-purchaser perspectives. Journal of Business Strategies, 19, p. 19-41, 2002. 
[64] C. N. Madu and A. A. Madu, Dimensions of e-quality. The International Journal of Quality \& Reliability Management, 19(3), p. 246-258, 2002. https://doi.org/10.1108/02656710210415668

[65] V. A. Zeithaml, Service excellence in electronic channels. Managing Service Quality, 12(3), p. 135-139, 2002. https://doi.org/10.1108/ 09604520210429187

[66] J. Santos, E-service quality: A model of virtual service quality dimensions. Managing Service Quality, 13(3), p. 233-246, 2003.

[67] M. Wolfinbarger and M. C. Gilly, eTailQ: Dimensionalizing, measuring and predicting etail quality. Journal of Retailing, 79(3), p. 183-198, 2003. https://doi.org/10.1016/S0022-4359(03)00034-4

[68] Z. Yang, R. T. Peterson, and S. Cai, Services quality dimensions of Internet retailing: An exploratory analysis. Journal of Services Marketing, 17(7), p. 685-700, 2003. https://doi.org/10.1108/ 08876040310501241

[69] S. Kim and L. Stoel, Apparel retailers: website quality dimensions and satisfaction. Journal of Retailing and Consumer Services, 11(2), p 109-117, 2004. https://doi.org/10.1016/S0969-6989(03)00010-9

[70] Z. Yang, M. Jun, and R. T. Peterson, Measuring customer perceived online service quality: Scale development and managerial implications. International Journal of Operations \& Production Management, 24(11), p. 1149-1174, 2004. https://doi.org/10.1108/014435 70410563278

[71] Z. Yang and X. Fang, Online service quality dimensions and their relationships with satisfaction: A content analysis of customer reviews of securities brokerage services. International Journal of Service Industry Management, 15(3), p. 302-326, 2004. https://doi.org/10.1108/09564230410540953

[72] S. Gounaris, S. Dimitriadis, and V. Stathakopoulos, Antecedents of perceived quality in the context of internet retail stores. Journal of Marketing Management, 21(7-8), p 669-700, 2005. http://dx.doi.org/10.1362/026725705774538390

[73] G. G. Lee and H. F. Lin, Customer perceptions of e-service quality in online shopping. International Journal of Retail \& Distribution Management, 33(2), p. $161-176, \quad 2005$. https://doi.org/10.1108/09590550510581485

[74] A. Parasuraman, V. A. Zeithaml, and A. Malhotra, ES-QUAL a multiple-item scale for assessing electronic service quality. Journal of Service Research, 7(3), p 213-233, 2005. https://doi.org/10.1177/1094670504271156

[75] M. Fassnacht and I. Koese, Quality of electronic services: Conceptualizing and testing a hierarchical model. Journal of Service Research, 9(1), p. 19-37, 2006. https://doi.org/10.1177/ 
1094670506289531

[76] M. Kim, J. H. Kim, and S. J. Lennon, Online service attributes available on apparel retail web sites: an E-S-QUAL approach. Managing Service Quality, 16, p. 51-77, 2006. https://doi.org/10.1108/09604520610639964

[77] T. Ahn, S. Ryu, and I. Han, The impact of Web quality and playfulness on user acceptance of online retailing. Information \& Management, 44(3), p. 263-275, 2007. https://doi.org/10.1016/j.im.2006.12.008

[78] E. Cristobal, C. Flavian, and M. Guinalİu, Perceived e-service quality (PeSQ). Managing Service Quality, 17(3), p. 317-340, 2007. https://doi.org/10.1108/09604520710744326

[79] C. Sohn and S. K. Tadisina, Development of e-service quality measure for internet-based financial institutions. Total Quality Management, 19(9), p 903-918, 2008. http://dx.doi.org/10.1080/14783360802224412

[80] H. Li and R. Suomi, A proposed scale for measuring e-service quality. Internationa Journal of $u$ - and e-Service, 2(1), p1-10, 2009.

[81] A. S. Rao and V. G. Rao, Service quality in e-commerce and strategic advantage: An empirical assessment. IUP Journal of Business Strategy, 10(2), p 50-66, 2013.

[82] J. Xu, I. Benbasat, and R. T. Cenfetelli, The nature and consequences of trade-off transparency in the context of recommendation agents. Qualitative Market Research, 38(2), p 379-406, 2014.

[83] A. Ellahi and R. H. Bokhari, Key quality factors affecting users' perception of social networking websites. Journal of Retailing \& Consumer Services, 20(1), p 120-129, 2013. https://doi.org/10.1016/j.jretconser.2012.10.013

[84] S. Cebi, A quality evaluation model for the design quality of online shopping websites. Electronic Commerce Research \& Applications, 12(2), p 124-135, 2013. https://doi.org/10.1016/j.elerap.2012.12.001

[85] G. Bressolles, F. Durrieu, and S. Senecal, A consumer typology based on e-service quality and e-satisfaction. Journal of Retailing \& Consumer Services, 21(6), p 889-896, 2014. https://doi.org/10.1016/j.jretconser.2014.07.004

[86] K. Al-Qeisi, C. Dennis, E. Alamanos, and C. Jayawardhena, Website design quality and usage behavior: Unified Theory of Acceptance and Use of Technology. Journal of Business Research, 67(11), p 22822290, 2014. https://doi.org/10.1016/j.jbusres.2014.06.016

[87] M. E. Gonzalez, G. Quesada, J. Davis, and C. Mora-Monge, Application of quality management tools in the evaluation of websites: The case of sports organizations. Quality Management Journal, 22(1), p 30-46, 2015.

[88] M. Blut, N. Chowdhry, V. Mittal, and C. Brock, E-service quality: A metaanalytic review. Journal of Retailing, 91(4), p 679-700, 2015. 
https://doi.org/10.1016/j.jretai.2015.05.004

[89] W. H. DeLone and E. R. McLean, Measuring e-commerce success: Applying the DeLone \& McLean information systems success model. International Journal of Electronic Commerce, 9(1), p 31-47, 2004.

[90] C. Yoon, Theory of planned behavior and ethics theory in digital piracy: An integrated model. Journal of Business Ethics, 100(3), p 405-417, 2011.

[91] I. Phau, A. Lim, J. Liang, and M. Lwin, Engaging in digital piracy of movies: a theory of planned behaviour approach. Internet Research, 24(2), p 246-266, 2014. https://doi.org/10.1108/IntR-11-2012-0243

[92] B. Sheehan, J. Tsao, and J. Pokrywczynski, Stop the Music! Journal of Advertising Research, 52(3), p 309-321, 2012. https://doi.org/ 10.2501/JAR-52-3-309-321

[93] D. J. Kim, D. L. Ferrin, and H. R. Rao, A trust-based consumer decision-making model in electronic commerce: The role of trust, perceived risk, and their antecedents. Decision Support Systems, 44(2), p 544-564, 2008. https://doi.org/10.1016/j.dss.2007.07.001

[94] P. A. Pavlou, L. Huigang, and X. Yajiong, Understanding and mitigating uncertainty in online exchange relationships: A principal-agent perspective. MIS Quarterly, 31(1), p 105-136, 2007.

[95] M. Koufaris, Applying the technology acceptance model and flow theory to online consumer behavior. Information Systems Research, 13(2), p 205-223, 2002.

[96] P. A. Pavlou and M. Fygenson, Understanding and predicting electronic commerce adoption: An extension of the theory of planned behavior. MIS Quarterly, 30(1), p. 115-143, 2006.

[97] D. Barclay, R. Thompson, and C. Higgins, The partial least squares (PLS) approach to causal modeling: Personal compuer adoption and use as an illustration. Technology Studies, 2(2), p 285-309, 1995.

[98] W. W. Chin, Modern methods for business research. In G. A. Marcoulides (Eds.), The Partial Least Squares Approach for Structural Equation Modeling (p 295-336). NJ, 1998.

[99] V. E. Vinzi, W. W. Chin, J. Henseler, and H. Wang, Eds., Handbook of Partial Least Squares: Concepts, Methods and Applications. Springer Handbooks of Computational Statistics, 2010.

[100]P. M. Podsakoff and D. W. Organ, Self-reports in organizational research: Problems and prospects. Journal of Management, 12(4), p 531-544, 1986. https://doi.org/10.1177/014920638601200408

[101] G. Peoples. What Apple music and Spotify's updated subscriber count really means. Retrieved on April 3, 2016, from http://www.billboard.com/articles/business/6836561/apple-music-spotifysubscriber-count-analysis

[102] Z. Locke, How to save the recording industry? Charge less. UCLA 
Entertainment Law Review, 16(1), p 79-88, 2009.

[103] A. G. Peace, D. F. Galletta, and J. Y. L. Thong, Software piracy in the workplace: A model and empirical test. Journal of Management Information Systems, 20(1), p 153-177, 2003. http://dx.doi.org/10.1080/07421222.2003.11045759 


\section{APPENDIX}

\section{Measurement Instrument}

General Attitude Towards Unauthorized Downloading - Adapted Scale ${ }^{103}$ [GATUD1] To me, unauthorized downloading of songs from P2P networks is $1=$ very bad; $7=$ very good

[GATUD2] To me, unauthorized downloading of songs from P2P networks is $1=$ very unpleasant; $7=$ very pleasant

[GATUD3] To me, unauthorized downloading of songs from P2P networks is $l=$ very foolish; $7=$ very wise

[GATUD4] To me, unauthorized downloading of songs from P2P networks is $l=$ very wrong; $7=$ very correct

[GATUD5] To me, unauthorized downloading of songs from P2P networks is $l=$ very unacceptable $;=$ very acceptable

Likelihood of Setting up an Account (Purchasing Intention) - New item [PI] After this study, how likely are you to set up a personal account at this website? $\quad l=$ very unlikely $-7=$ very likely

Unauthorized Downloading Intention - Adapted Scale ${ }^{103}$

[UDI1] I may download unauthorized copies of songs from a P2P network in the future to avoid using this website for acquiring music. (Assume the song is available only from a P2P network or your assigned website.)

$1=$ strongly disagree $-7=$ strongly agree

[UDI2] If I had the opportunity, I would download unauthorized songs from a P2P network to avoid using this website for acquiring music. (Assume the song is available only from a P2P network or your assigned website.)

$1=$ strongly disagree $-7=$ strongly agree

[UDI3] I would never download unauthorized songs from a P2P network to avoid using this website for acquiring music. (Assume the song is available only from a P2P network or your assigned website.

$1=$ strongly disagree $-7=$ strongly agree

Product Cost - Adapted Scale ${ }^{103}$

[PC1] I feel that the price for music at this website is very inexpensive.

$1=$ strongly disagree $-7=$ strongly agree

[PC2] In my opinion, music at this website is

$1=$ very inexpensive $-4=$ just right $-7=$ very expensive

[PC3] If I wanted to acquire music from this website today, it would cost me too much money. $1=$ strongly agree $-7=$ strongly disagree 
Perceived Product Format Usefulness - Adapted Scale ${ }^{56}$

[PPFU1] The song format is useful.

[PPFU2] The song format improves my overall music consumption experience.

[PPFU3] The song format improves my overall music consumption performance.

[PPFU4] The song format does not enable me to consume music in the way I prefer.

[PPFU5] The song format enhances my overall effectiveness in consuming music. [PPFU6] The song format makes it easier to consume music.

All items: $1=$ strongly disagree $-7=$ strongly agree

Perceived Product Format Enjoyment - Adapted Scale ${ }^{57}$

[PPFE1] To me, the song format from this website is enjoyable.

[PPFE2] To me, the song format from this website is exciting.

[PPFE3] To me the song format from this website is unpleasant.

[PPFE4] To me, the song format from this website is boring.

[PPFE5] To me, the song format from this website is interesting.

[PPFE6] To me, the song format from this website is dull.

All items: $1=$ strongly disagree $-7=$ strongly agree

Perceived System Quality - Adapted Scale ${ }^{77}$

[PSQ1] This website has an appropriate style of design for this type of website.

[PSQ2] This website has easy navigation to information.

[PSQ3] This website has fast response and transaction processing.

[PSQ4] This website does not keep personal information secure from exposure

[PSQ5] I can use this website when I want to use it

[PSQ6] This website has good functionality relevant to this type of website

[PSQ7] This website does not keep error-free transactions.

[PSQ8] This website creates an audio-visual experience.

All items: $1=$ strongly disagree $-7=$ strongly agree

Perceived Information Quality - Adapted Scale ${ }^{77}$

[PIQ1] This website has sufficient content where I expect to find information

[PIQ2] This website provides complete information.

[PIQ3] This website provides site-specific information.

[PIQ4] This website does not provide accurate information.

[PIQ5] This website provides timely information.

[PIQ6] This website does not provide reliable information.

[PIQ7] This website communicates information in an appropriate format.

All items: $1=$ strongly disagree $-7=$ strongly agree 
Perceived MSS Usefulness - Adapted Scale ${ }^{56}$

[PMUA1] The website is useful.

[PMUA2] The website saves me time.

[PMUA3] The website helps me be productive.

[PMUA4] The website makes the task I want to accomplish easier to get done.

[PMUA5] The website helps me be more effective.

[PMUA6] The website requires the fewest steps to accomplish what I want to do with it.

All items: $1=$ strongly disagree $-7=$ strongly agree

Perceived MSS Enjoyment - Adapted Scale ${ }^{57}$

[PME1] To me, the website is enjoyable.

[PME2] To me, the website is exciting.

[PME3] To me, the website is unpleasant.

[PME4] To me, the website is boring.

[PME5] To me, the website is interesting.

[PME6] To me, the website is dull.

All items: $1=$ strongly disagree $-7=$ strongly agree

Perceived MSS Ease of Use - Adapted Scale ${ }^{56}$

[PMEOU1] The website is easy to use.

[PMEOU2] It is easy to become skillful at using the website.

[PMEOU3] Learning to operate the website is NOT easy.

[PMEOU4] The website is flexible to interact with.

[PMEOU5] My interaction with the website is clear and understandable.

All items: $1=$ strongly disagree $-7=$ strongly agree 